\title{
Development and Validation of a New RP-HPLC-UV Method for the Simultaneous Determination of Phenytoin Impurities, Benzophenone, and Benzil
}

\author{
Bunleu Sungthong ${ }^{1 *}$, Ruchilak Rattarom ${ }^{1}$, Vilasinee Hirunpanich Sato ${ }^{2}$ and Hitoshi Sato ${ }^{3}$ \\ 'Pharmaceutical Chemistry and Natural Products Research Unit, Faculty of Pharmacy, Mahasarakham University, \\ Kantharawichai District, Maha Sarakham, 44150, Thailand \\ ${ }^{2}$ Department of Pharmacology, Faculty of Pharmacy, Mahidol University, Rajathevi, Bangkok, 10400, Thailand \\ ${ }^{3}$ School of Pharmacy, Showa University, 1-5-8 Hatanodai, Shinagawa-ku, Tokyo, 142-8666, Japan
}

Received: 25 January 2018; accepted: 01 July 2018

\begin{abstract}
A new reversed-phase high-performance liquid chromatographic method with ultraviolet detection (RP-HPLC-UV) for simultaneous determination of phenytoin impurities, benzophenone and benzil, was developed and validated according to the International Council for Harmonization (ICH) guidelines. Chromatographic separation was performed on a $\mathrm{C}_{8}$ column using acetonitrile $-1 \%$ acetic acid $(60: 40, v / v)$. The correlation coefficients of the calibration lines were greater than 0.999 with $95 \%$ confident interval of $y$-intercept over the origin. The analytical method showed good precision, intra-day precision $\leq 1.00$ and inter-day precision $\leq 1.53$. The standard solution of each compound exhibited good stability $99.18-99.70 \%$, after storage at room temperature for $24 \mathrm{~h}$. The limit of detection (LOD) and limit of quantification (LOQ) were 0.0015 and $0.005 \mu \mathrm{g} / \mathrm{mL}$, respectively. The resolution of the impurities was $2.935 \pm 0.009$. The proposed analytical method was successfully applied to determine the amount of benzophenone and benzil in marketed products. The amount of benzophenone was found at $3.09-5.91 \times 10^{-3} \%$, while benzil was not detected in the samples.
\end{abstract}

Keywords: benzil, benzophenone, $\mathrm{C}_{8}$ column, HPLC, phenytoin impurities

\section{Introduction}

Drug impurities are generally classified into 3 categories; organic, inorganic impurities, and residual solvents. Based on structure similarities, organic impurities are often the matter of concern for the separation and purification of drug substances. Organic impurities of drugs are mostly derived from manufacturing or storage process [1] and may include starting materials, by-products, intermediates, and degradation products [2, 3], as well as isomeric impurity [4]. For example, citadiol is an intermediate of citalopram synthesis [5]. Impurities existing in drug products influence not only drug quality, but also patients' safety, since they may exert undesired pharmacological or toxicological activities [6]. Based on safety and toxicological concerns, genotoxicity and general toxicity studies have to be conducted when impurities greater than qualification threshold are present in drug products $[7,8]$.

Phenytoin (5,5-diphenylimidazolidine-2,4-dione) is an antiepileptic drug for the treatment of tonic-clonic seizures and partial seizures [9]. The drug is synthesized via benzil intermediate, which could remain with synthetic phenytoin, unless appropriate purification is performed. Moreover, during manufacturing and storage processes, degradation of phenytoin can generate benzophenone as a new compound. The possible impurities of phenytoin are shown in Figure 1. With a short term exposure of benzophenone, it reportedly caused irritations of eyes, respiratory tract, and skin [10]. Moreover, ingestion of benzophenone has been reported to increase the incidence of liver carcinogenicity and renal toxicity [11].

*Author for correspondence: bunleu.s@msu.ac.th; tel/fax: +66 43754360.
Drug impurities have been analyzed by a variety of techniques such as, ultraviolet-visible (UV-vis) spectrophotometry, high-performance thin-layer chromatography (HPTLC), high-performance liquid chromatography (HPLC), and capillary electrophoresis (CE). Among these methods, HPLC is the most popular method for quantitative analysis of drugs and impurities, due to its selectivity, precision, and accuracy [12, 13]. The United States Pharmacopeia, USP 30 [14], recommended an HPLC method to determine benzophenone using $\mathrm{C}_{18}$ stationary phase. The amount of benzophenone in drug substances and drug products analyzed by the method is limited to $0.1 \%$. Several methods to analyze phenytoin impurities have been investigated. For instance, Walash et al. developed a spectrophotometric method to determine benzophenone impurity [10]. Another method using multi-wavelength UV-vis spectrophotometry was also developed for benzil and benzophenone impurities [15]. A polarographic method for benzophenone impurity in phenytoin products was also developed and validated as a very sensitive method for benzophenone co-existing with phenytoin [16]. However, HPLC methods for the simultaneous determination of benzophenone and benzil impurities in phenytoin have not been developed yet. Therefore, the objective of this study was to develop a simple, rapid, and accurate analytical method for simultaneous quantification of benzophenone and benzil in phenytoin products.

\section{Experimental}

Standard, Chemicals, and Reagents. Phenytoin sodium was purchased from Acros Organics (Geel, Belgium), and benzophenone and benzil was from Sigma Aldrich (St. Louis, MO, USA). Methanol and acetonitrile were of HPLC-grade,

This is an open-access article distributed under the terms of the Creative Commons Attribution-NonCommercial 4.0 International License (https://creativecommons.org/licenses/by-nc/4.0/), which permits unrestricted use, distribution, and reproduction in any medium for non-commercial purposes, provided the original author and source are credited, a link to the CC License is provided, and changes - if any - are indicated. 


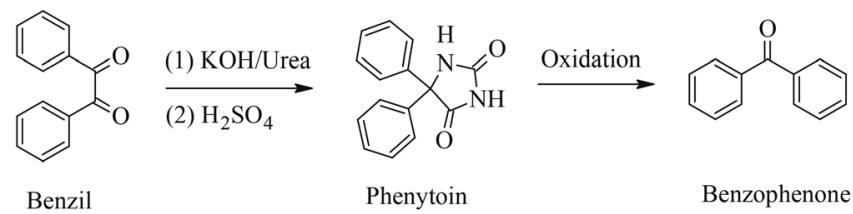

Figure 1. Structure of phenytoin and its impurities (benzil and benzophenone)

obtained from Wako Chemicals (Osaka, Japan). All other chemicals and solvents were of analytical grade. Ultra-purified water was generated by Milli-Q academic A10 with a $0.22-\mu \mathrm{m}$ Millipak ${ }^{\circledR}$ filter (Millipore, Darmstadt, Germany).

Instrumentation. Experiments were operated using a Prominence liquid chromatographic system (Shimadzu Corp., Kyoto, Japan) consisted of a quaternary pump liquid chromatograph (LC-20AT) with a degasser (DGU-20A 3 ), a $\mathrm{UV} / \mathrm{Vis}$ detector (SPD-20A), and a communication bus module (CBM-20A). Samples were introduced into the analytical system via $7725 \mathrm{i}$ Rheodyne ${ }^{\circledR}$ loop, $20 \mu \mathrm{L}$. The analytical column was packed with $5-\mu \mathrm{m}$ Luster $^{\mathrm{TM}} \mathrm{C}_{8}$ (octylsilyl silica gel), $250 \mathrm{~mm} \times 4.6 \mathrm{~mm}$ (Dikma Technologies Inc., Lake Forest, CA, USA). Mobile phases were composed of methanol or acetonitrile containing acetic acid. The flow rate of the mobile phase system was set at $1.0 \mathrm{~mL} / \mathrm{min}$ at ambient temperature. The chromatograms were collected at $254 \mathrm{~nm}$. All analyses were conducted using Shimadzu Labsolution software implemented in a personal computer, ESPRIMO (Fujitsu, Tokyo, Japan).

Method Development. Standard stock solutions of phenytoin sodium, benzophenone, and benzil were prepared in methanol and subsequently diluted to desired concentrations with 50\% methanol. Mobile phase used in method development consisted of 50,60 , or $70 \%$ organic phase (methanol or acetonitrile) containing 1, 2, or 3\% glacial acetic acid. The mobile phase was then filtered and degassed prior to use. The criteria for decision making were the resolution of compounds (greater than 2.0 as recommended by the USP), total analysis time (not exceeding $30 \mathrm{~min}$ ), and separation from solvent front.

Method Validation. The optimized method was further validated according to the International Council for Harmonization (ICH guideline Q2(R1), validation of analytical procedures: text and methodology) [17]. Phenytoin sodium and impurities (benzophenone and benzil) from stock solutions were diluted with $50 \%$ methanol to obtain final concentration of $0.1-8 \mu \mathrm{g} / \mathrm{mL}(0.002-0.16 \%$ corresponding to $5 \mathrm{mg} / \mathrm{mL}$ phenytoin sodium). The validation parameters composed of precision, \%recovery, stability of standard solution, linearity and range, limit of detection (LOD), and limit of quantitation (LOQ).

Precision. Precision of analytical methods was assessed regarding repeatability (intra-day precision) and intermediate precision (inter-day precision). Two concentrations (low and high concentrations at 1 and $6 \mathrm{mg} / \mathrm{mL}$, respectively) of standard impurities within a linearity range were evaluated. Each concentration was analyzed in 6 replications on the same day for repeatability and continued with each 6 replications for 2 consecutive days for inter-day precision. Standard deviation, pooled standard deviation, and relative standard deviation (RSD) of intra-day and inter-day precisions were calculated.

Percent Recovery. Recovery of extraction was determined by a standard addition method. Samples were spiked with known concentrations of 1 and $6 \mu \mathrm{g} / \mathrm{mL}$. The extraction process was performed in accordance with a method applied for phenytoin capsules and tablets, as described later. Finally, the recovery of sample extraction was calculated as percentage relative to the total amount added.
Stability of Standard Solutions. To ensure accurate and precise results, the standard solutions under the experimental condition have to be stable. Standard solutions were freshly prepared at concentrations of 1 and $6 \mathrm{mg} / \mathrm{mL}$ in $50 \%$ methanol and immediately analyzed within $24 \mathrm{~h}$ at air-conditioned temperature $\left(28-30{ }^{\circ} \mathrm{C}\right)$. The results were reported as percent remaining of 1 and $6 \mu \mathrm{g} / \mathrm{mL}$ for benzophenone and benzil, respectively.

Linearity and Range. Linearity and range were evaluated over $0.1-8 \mu \mathrm{g} / \mathrm{mL}$ (corresponding to $0.002-0.16 \%$ of phenytoin sodium) for benzophenone and benzil standards. As recommended in $\mathrm{Q} 2(\mathrm{R} 1)$ of the $\mathrm{ICH}$ guidelines, a minimum of 5 concentrations were tested. According to USP 30, the limit of benzophenone in samples should not exceed $0.1 \%$ of the corresponding phenytoin sodium. Therefore, the range of standard concentration has to be covered from reporting level, $0.05 \%$ compared to a parent drug, to $120 \%$ of the specification. In this study, 6 concentrations of the standards were evaluated according to linearity and range of $0.1,1,2,4,6$, and $8 \mu \mathrm{g} / \mathrm{mL}$ corresponding to $0.002-0.16 \%$. Each concentration was analyzed in triplicate.

Limit of Detection and Limit of Quantitation. Limit of detection (LOD) and limit of quantitation (LOQ) were assessed according to the ICH guideline Q2(R1). There are several methods for determining LOD and LOQ such as, (1) signal-tonoise ratios, and (2) standard deviation of response and slope approaches. In this study, signal-to-noise ratios of 3:1 and 10:1 were employed for the determination of LOD and LOQ, respectively. From the lowest concentration of the linearity range, the standard solution was further diluted and injected to the HPLC system until the requirement had been met.

Method Application. Phenytoin sodium capsules and tablets were purchased in Bangkok, Thailand. Each sample was weighed and calculated with a minimum of 20 units to obtain an equivalent weight of the active ingredient. The equivalent weight of phenytoin sodium at $5 \mathrm{mg} / \mathrm{mL}$ of each sample was prepared in $50 \%$ methanol. The sample was mechanically mixed for $5 \mathrm{~min}$ and subsequently sonicated for additional $10 \mathrm{~min}$. The sample was then filtered through a polytetrafluoroethylene (PTFE) syringe filter with $0.45-\mu \mathrm{m}$ pore size (RaphiLe Bioscience, China). The filtrate was injected in triplicate into the HPLC system and quantified based on the calibration curve of each impurity. Finally, the amount of the impurities was converted into percentage relative to the actual value of phenytoin sodium.

\section{Results and Discussion}

Method Development. We aimed to develop an analytical method with a simple chromatographic condition for the simultaneous determination of impurities, benzophenone, and benzil, co-existing with phenytoin sodium in marketed products. As stated in USP 30, the mobile phase for related substances consisted of $0.05 \mathrm{M}$ monobasic ammonium phosphate buffer $\mathrm{pH} 2.5$, acetonitrile, and methanol (45:35:20) using $\mathrm{C}_{18}$ as a stationary phase. In this study, the method was developed as functions of type of organic solvent (methanol or acetonitrile), amount of acetic acid (1-3\%), and ratio of organic phase to aqueous phase $(50-70 \%)$. The optimal 
Table 1. Chromatographic parameters of the analytical method

\begin{tabular}{lcc}
\hline Parameters & Benzophenone $^{a}$ & Benzil $^{a}$ \\
\hline Relative standard deviation of retention time (\%) & 0.206 & 0.220 \\
Relative standard deviation of area (\%) & 0.767 & 1.037 \\
Resolution (mean \pm sd) & - & $2.935 \pm 0.009$ \\
Tailing factor $($ mean \pm sd) & $1.095 \pm 0.003$ & $1.087 \pm 0.005$ \\
Number of theoretical plate, $N$ (mean $\pm \mathrm{sd})$ & $15,647 \pm 45.769$ & $15,815 \pm 75.234$ \\
Capacity factor, $k$ ' (mean $\pm \mathrm{sd})$ & $2.816 \pm 0.014$ & $3.191 \pm 0.016$ \\
Selectivity factor, $\alpha$ (mean \pm sd) & - & $1.133 \pm 0.000$ \\
$\quad{ }^{a}$ At $1 \mu \mathrm{g} / \mathrm{mL}(n=6)$. & & \\
\hline
\end{tabular}

method was selected based on the total analysis time (not exceeding $30 \mathrm{~min}$ ) and the resolution of compounds (more than 2.0 recommended by Center for Drug Evaluation and Research) [18]. The stationary phase used in the study was $\mathrm{C}_{8}$, which has less hydrophobicity compared with $\mathrm{C}_{18}$. The advantage of using $\mathrm{C}_{8}$ over $\mathrm{C}_{18}$ is that a faster analysis time can be obtained for hydrophobic compounds. Based on the polarity of phenytoin and its impurities, $\mathrm{C}_{8}$ could be a better stationary phase to obtain a shorter total analysis time.

The separation of benzophenone and benzil was used as a critical point of the method development. At 50\% methanol, the retention times of benzophenone and benzil were longer than $30 \mathrm{~min}$. Shorter retention times were obtained, when $60 \%$ methanol was used as a mobile phase; however, the resolution of benzophenone and benzil was less than 2. Increasing concentration of methanol to $70 \%$, co-elution of phenytoin was observed. In addition, resolution of benzophenone and benzil was less than 1.0. Good resolutions of the separation of phenytoin and its impurities were not achieved with the mobile phases consisting of methanol. The better resolution and lower pressure of the HPLC system were obtained when acetonitrile was employed instead. The advantages of acetonitrile over methanol were the shorter analysis time and better resolution. The resolution of benzophenone and benzil using 50, 60 , and $70 \%$ acetonitrile were approximately $4.5,2.8$, and 1.1 , respectively. Adding more amounts $(1,2$, and $3 \%$ ) of acetic acid into the mobile phase did not show any effects on the resolution; therefore, $1 \%$ acetic acid was constantly used for method validation. As a result of total analysis time and resolution of benzophenone and benzil over 2.0, a mixture of acetonitrile and $1 \%$ acetic acid in water $(60: 40)$ was shown to be the optimal condition for further experiment. The chromatographic parameters of benzophenone and benzil were examined with regard to relative standard deviation of retention time and peak area, resolution, tailing factor, number of theoretical plates, capacity factor, and selectivity factor, as summarized in Table 1. These parameters, resolution $>2$ and selectivity factor $>1.1$, assured that baseline separation of benzophenone and benzil can be obtained with low deviation by the developed method. Typical chromatogram of the analytical method is showed in Figure 2.

Method Validation. Validation of the analytical method was performed according to the ICH guideline Q2(R1). Validation parameters are listed in Table 2. Repeatability (intra-day precision of 1 and $6 \mu \mathrm{g} / \mathrm{mL}$ ) was presented as percentage relative standard deviation (\%RSD) and ranged between $0.49-1.00 \%$. For inter-day precision, \%RSD of both concentrations ranged from $0.85-1.53 \%$. The percentage of extraction (\%recovery) of impurities from sample matrix was examined using standard solutions containing known amounts of benzophenone and benzil. Benzophenone showed higher percent recovery compared with benzil, close to $100 \%(99.09$ \pm 0.21 and $100.28 \pm 0.34$ for low and high concentrations added, respectively). In the case of benzil, \%recovery was lower (93.64 \pm 0.98 and $95.56 \pm 0.18$, for low and high concentrations added, respectively). The low percent recovery of benzil may be due to adsorption of the substance within matrix or glassware.

Stability of the standard solutions was evaluated to ensure that the amounts of standard substances remain in the same amount throughout the analysis time. For the optimized method, benzophenone and benzil showed a good stability close to $100 \%$ compared with the fresh preparation. Linearity and range of both impurities showed good fit over $0.1-8 \mu \mathrm{g} / \mathrm{mL}$ with the correlation coefficients of 0.9989 and 0.9999 for benzophenone and benzil, respectively. This method showed a

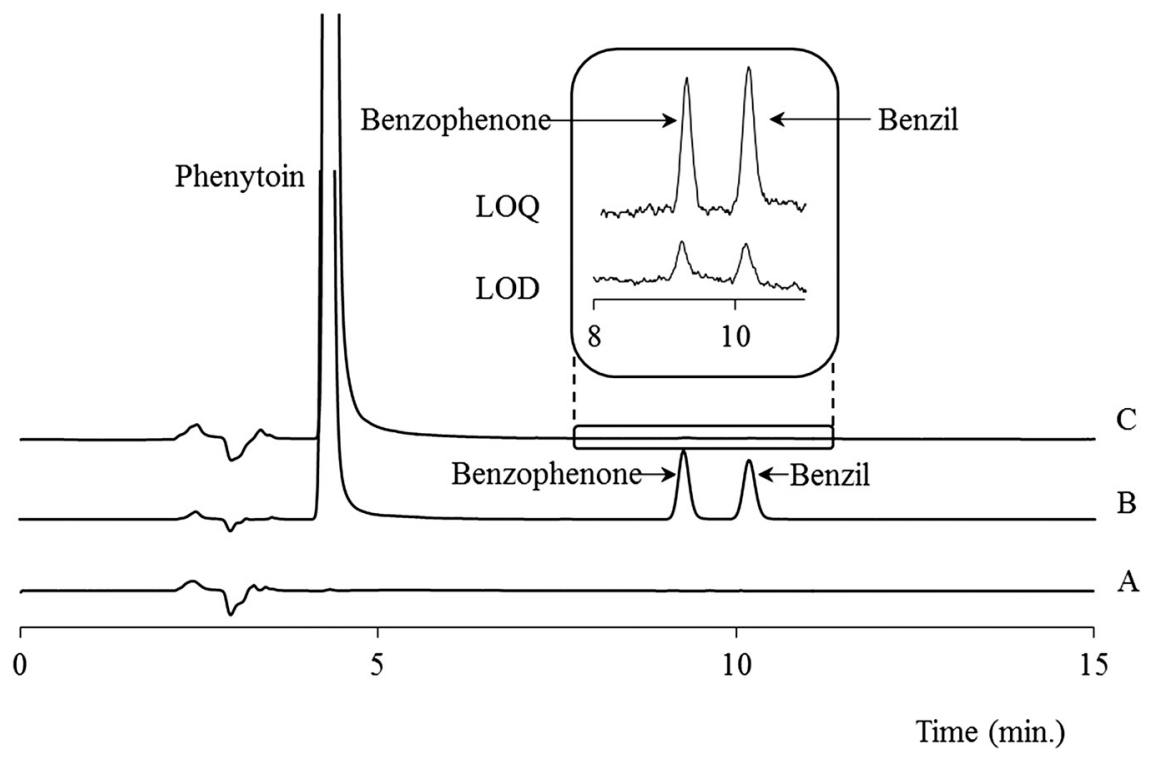

Figure 2. Chromatogram of blank (A); $5 \mathrm{mg} / \mathrm{mL}$ phenytoin with $1 \mu \mathrm{g} / \mathrm{mL}$ benzophenone and $1 \mu \mathrm{g} / \mathrm{mL}$ benzil (B); LOD $=0.0015 \mu \mathrm{g} / \mathrm{mL}$ and $\mathrm{LOQ}=0.005 \mu \mathrm{g} / \mathrm{mL}(\mathrm{C})$ using acetonitrile and $1 \%$ acetic acid $(60: 40)$ as a mobile phase 
Table 2. Validation data of phenytoin impurities (benzophenone and benzil)

\begin{tabular}{|c|c|c|}
\hline Validation parameters & Benzophenone & Benzil \\
\hline \multicolumn{3}{|l|}{ Precision (\% RSD) } \\
\hline \multicolumn{3}{|l|}{ Repeatability $(n=6)$} \\
\hline Low concentration $(1 \mu \mathrm{g} / \mathrm{mL})$ & 0.77 & 1.00 \\
\hline \multicolumn{3}{|l|}{ Inter-day precision ( 3 days, $n=18$ ) } \\
\hline Low concentration $(1 \mu \mathrm{g} / \mathrm{mL})$ & 1.26 & 1.53 \\
\hline High concentration $(6 \mu \mathrm{g} / \mathrm{mL})$ & 0.85 & 0.95 \\
\hline \multicolumn{3}{|l|}{ Percent Recovery } \\
\hline High concentration $(6 \mu \mathrm{g} / \mathrm{mL})$ & $100.28 \pm 0.34$ & $95.56 \pm 0.18$ \\
\hline \multicolumn{3}{|c|}{ Stability of standard solution (at ambient temperature, $24 \mathrm{~h}$ ) } \\
\hline Low concentration $(1 \mu \mathrm{g} / \mathrm{mL}, \%$ remaining) & $99.18 \pm 1.97$ & $99.70 \pm 0.66$ \\
\hline High concentration $(6 \mu \mathrm{g} / \mathrm{mL}, \%$ remaining $)$ & $99.55 \pm 0.17$ & $99.55 \pm 0.45$ \\
\hline Linear equation (concentration vs peak area) & $y=115,020 x-7,336.6$ & $y=108,318 x-1,469.6$ \\
\hline Range $(\mu \mathrm{g} / \mathrm{mL}, 5 \text { points })^{a}$ & $0.1-8$ & $0.1-8$ \\
\hline $95 \%$ Confident interval of $y$-intercept & $-19,270.1$ to $4,596.8$ & $-4,471.8$ to $1,532.7$ \\
\hline Correlation coefficient & 0.9989 & 0.9999 \\
\hline Limit of quantitation (LOQ, $\mu \mathrm{g} / \mathrm{mL})$ & 0.005 & 0.005 \\
\hline
\end{tabular}

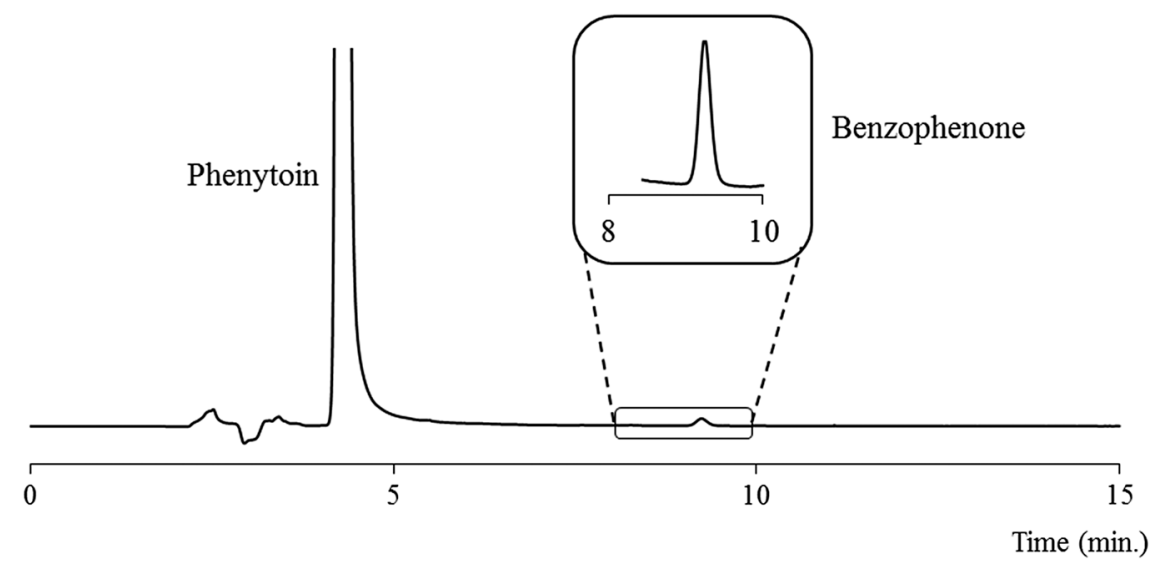

Figure 3. Chromatogram of phenytoin capsule sample no. 1

sufficient linearity $(\geq 0.999)$ according to Center for Drug Evaluation and Research [18], which is a better correlation coefficient than that with an reversed-phase HPLC (RP-HPLC) method published previously by Jeyaprakash et al., 0.995 [19]. Within $95 \%$ confident interval of the $y$-intercept, the regression lines of both compounds ranged across 0 . Moreover, LOD and LOQ were evaluated on a basis of signal-to-noise ratio at 3:1 and 10:1, respectively.

A polarographic method for benzophenone impurity in phenytoin was developed by Razak et al. [16], where the impurity was detected at $2.5 \times 10^{-3} \mathrm{ng} / \mathrm{mL}$, while the impurities of this method was detected at $1.5 \mathrm{ng} / \mathrm{mL}$. Although LOD and LOQ of the present method were higher than polarographic method, the present method indicated a sufficient quantitative analysis in accordance with USP30 and BP 2007 requirements [14, 20]. This method can be applied to determine the concentration of benzophenone and benzil at $0.1 \mu \mathrm{g} / \mathrm{mL}$ with low percent RSD ( 0.42 and 0.26 , respectively), which was lower than the polarographic method for benzophenone determination $(0.4 \mu \mathrm{g} / \mathrm{mL}$ with $\% \mathrm{RSD}$ of $2 \%)$. Several methods using UV-vis derivative spectrophotometry were also applied for benzophenone impurities in phenytoin products [10]. The LOD and LOQ of the spectrophotometric methods were relatively higher than the proposed method and the polarographic method, which ranged between $0.04-0.11 \mu \mathrm{g} / \mathrm{mL}$ and $0.13-0.34 \mu \mathrm{g} / \mathrm{mL}$, respectively. This method was performed based on the calibration range over $0.1-8 \mu \mathrm{g} / \mathrm{mL}$. For quantitative analysis of benzophenone impurities at lower concentrations, further verification should be carried out. At all events, our method is advantageous in that both impurities of benzophenone and benzil can be simultaneously measured.

Method Application. The proposed analytical method was applied to analyze the intermediate, benzil, and the degrade product, benzophenone, in marketed products. The chromatogram of phenytoin sodium capsule sample no. 1 was shown in Figure 3. Table 3 indicated that benzophenone, derived from the oxidation of phenytoin [21], was found in the marketed products of phenytoin at approximately $0.003-$ $0.006 \%$ of the active ingredient. According to the requirement in USP 30, benzophenone found in samples was less than the allowance, $0.1 \%$ [14]. In the case of benzil, no corresponding peak was detected in all samples.

Table 3. Amounts of impurities in the marketed products of phenytoin

\begin{tabular}{|c|c|c|c|c|}
\hline \multirow[t]{2}{*}{ Product } & \multicolumn{2}{|c|}{ Benzophenone } & \multicolumn{2}{|c|}{ Benzil } \\
\hline & $\begin{array}{c}\% \text { impurity }^{a} \\
\left(\times 10^{-3}\right)\end{array}$ & $\begin{array}{l}\mu g \text { per } \\
\text { cap/tab }\end{array}$ & $\begin{array}{c}\text { \% impurity } \\
\left(\times 10^{-3}\right)\end{array}$ & $\begin{array}{l}\mu g \text { per } \\
\text { cap/tab }\end{array}$ \\
\hline $\begin{array}{l}\text { Capsule } 1 \\
\text { (100 mg/cap) }\end{array}$ & 5.91 & 5.91 & $\mathrm{ND}^{b}$ & ND \\
\hline $\begin{array}{l}\text { Capsule } 2 \\
\text { (100 mg/cap) }\end{array}$ & 3.12 & 3.12 & ND & ND \\
\hline $\begin{array}{l}\text { Tablet } 1 \\
(50 \mathrm{mg} / \mathrm{tab})\end{array}$ & 3.09 & 1.55 & ND & ND \\
\hline \multicolumn{5}{|c|}{$\begin{array}{l}{ }^{a} \text { The amounts of impurities corresponding to } 5 \mathrm{mg} / \mathrm{mL} \text { phenytoin } \\
\text { sodium }(n=3) \text {. } \\
{ }^{b} \mathrm{ND}=\text { not detected. }\end{array}$} \\
\hline
\end{tabular}




\section{Conclusion}

The developed analytical method was performed according to the ICH guideline. A simple simultaneous determination of phenytoin impurities, benzophenone and benzil has been obtained a complete separation with low deviation. The method was also applicable to analyze the impurities in the marketed products of phenytoin.

Acknowledgment. This research was financially supported by Mahasarakham University Research Support and Development Fund.

\section{References}

1. Whelan, L. C.; Geary, M.; Sweetman, P. J. Chrom. Sci. 2014, 52, 1267-1272.

2. International Council for Harmonisation Guidelines (ICH), Q3A(R2) Impurities in New Drug Substances. 2006, http://www. ich.org/fileadmin Public_Web_Site/ICH_Products/Guidelines/Quality/Q2_R1/Step4/

Q2_R 1 Guideline.pdf (Accessed September 27, 2015).

3. Pyla, S. R. M.; Sahu, P. K.; Srinivas, K. Acta Chromatogr. 2017, 29 , 207-217.

4. Paczkowska, M.; Zalewski, P.; Garbacki, P.; Talaczynska, A.; Krause, A.; Cielecka-Piontek, J. Chromatographia 2014, 77, 1497-1501.

5. Sungthong, B.; Jác, P.; Scriba, G. K. E. J. Pharm. Biomed. Anal. 2008, 46, 959-965.

6. Pan, C. K.; Liu, F.; Motto, M. J. Pharm. Sci. 2011, 100, 1230-1259.

7. International Council for Harmonisation Guidelines, Q3B(R2) Impurities in New Drug Products. 2006, http://www.ich.org/fileadmin/
Public_Web_Site/ICH_Products/Guidelines/Quality/Q3B_R2/Step4/

Q3B R 2 Guideline.pdf (Accessed September 27, 2015)

$\overline{8}$. Venugopal, N.; Reddy, A. V. B.; Madhavi, G. J. Pharm. Biomed. Anal. 2014, 90, 127-133.

9. Gagne, J. J.; Kesselheim, A. S.; Choudhry, N. K.; Polinski, J. M.; Hutchins, D.; Matlin, O. M.; Brennan, T. A.; Avorn, J.; Shrank, W. H. Epilepsy \& Behav. 2015, 52, 14-18.

10. Walash, M. I.; Rizk, M. S.; Sheribah, Z. A.; Salim, M. M. Chem Cent. J. 2011, 5, 85 .

11. US Department of Health and Human Services, Toxicology and Carcinogenesis Studies of Benzophenone (CAS No. 119-61-9) in F344/N Rats and B6C3F1 Mice (Feed Studies), 2015, http://ntp. niehs.nih.gov/ ntp/htdocs/lt_rpts/tr533.pdf (Accessed November 16, 2015).

12. Pai, S.; Sawant, N. Indian J. Pharm. Educ. Res. 2017, 51, 388-392.

13. Zalewski, P.; Cielecka-Piontek, J.; Garbacki, P.; Jelinska, A.; Karazniewicz-Lada, M. Chromatographia 2013, 76, 387-391.

14. The United Pharmacopeia 38 and the National Formulary 33 The United States Pharmacopeial Convention, Rockville, MD, USA, 2015 pp. 4865-4866.

15. Korde, P.; Pai, P. N. S. Asian J. Chem. 2014, 26, 3823-3826.

16. Razak, O. A.; Gazy, A. A.; Wahbi, A. M. J. Pharm. Biomed. Anal. 2002, 28, 613-619.

17. International Council for Harmonisation Guidelines, Q2(R1) Validation of Analytical Procedures: Text and Methodology, 2005, http://www. ich.org/ fileadmin/Public_Web_Site/ICH_Products/Guidelines/Quality/Q2_R1/Step4/

Q2 R1 Guideline.pdf (Accessed September 28, 2015).

18. Center for Drug Evaluation and Research, Food and Drug Administration, Reviewer Guidance: Validation of Chromatographic Methods, 1994, http://www. fda.gov/cder (Accessed September 17, 2015).

19. Jeyaprakash, M. R.; Sireesha, V.; Meyyanathan, S. N. Asian J. Pharm. Anal. Med. Chem. 2013, 1(2), 79-87.

20. British Pharmacopoeia 2015 Volume II, British Pharmacopoeial Commission, London, UK, 2015, pp. II 564-566.

21. Philip, J.; Halcomb, J.; Fusari, S. A. Analytical Profiles of Drug Substances Academic Press, Orlando, 1984, pp. 417-445. 